\title{
Non-surgical management of knee osteoarthritis: comparison of ESCEO and OARSI 2019 guidelines
}

Nigel K. Arden ${ }^{1,2,5, \S}$, Thomas A. Perry ${ }^{1+\S}$, Raveendhara R. Bannuru ${ }^{3}$, Olivier Bruyère ${ }^{4,5}$, Cyrus Cooper $^{2,5}$, Ida K. Haugen ${ }^{6}$, Marc C. Hochberg ${ }^{7}$, Timothy E. McAlindon ${ }^{3}$, Ali Mobasheri ${ }^{9,10,11^{*}}$ and Jean-Yves Reginster ${ }^{5,8^{*}}$

${ }^{1}$ Versus Arthritis Centre for Sport, Exercise and Osteoarthritis, University of Oxford, Oxford, UK.

${ }^{2}$ MRC Lifecourse Epidemiology Unit, University of Southampton, Southampton General Hospital, Southampton, UK.

${ }^{3}$ Center for Treatment Comparison and Integrative Analysis, Division of Rheumatology, Tufts Medical Center, Boston, MA, USA.

${ }^{4}$ Division of Public Health, Epidemiology and Health Economics, University of Liège, CHU Sart Tilman, 4000, Liège, Belgium.

${ }^{5}$ WHO Collaborating Centre for Public Health Aspects of Musculoskeletal Health and Aging, Liège, Belgium.

${ }^{6}$ Department of Rheumatology, Diakonhjemmet Hospital, Oslo, Norway.

${ }^{7}$ Departments of Medicine and Epidemiology and Public Health, University of Maryland School of Medicine, Baltimore, Maryland, USA.

${ }^{8}$ Chair for Biomarkers of Chronic Diseases, Biochemistry Department, College of Science, King Saud University, Riyadh, Saudi Arabia.

${ }^{9}$ Research Unit of Medical Imaging, Physics and Technology, University of Oulu, Oulu, Finland.

${ }^{10}$ Department of Regenerative Medicine, State Research Institute Centre for Innovative Medicine, Vilnius, Lithuania.

${ }^{11}$ UMC Utrecht, Departments of Orthopedics, Rheumatology and Clinical Immunology, Utrecht, The Netherlands.

${ }^{\S}$ These authors contributed equally.

*These authors jointly supervised this work.

temail: thomas.perry@ndorms.ox.ac.uk 


\begin{abstract}
Knee osteoarthritis $(\mathrm{OA})$ is a heterogeneous disease associated with substantial effects on quality of life, and its clinical management is difficult. Among the several available guidelines for the management of knee OA, those from OARSI and ESCEO were updated in 2019. Here, we examine the similarities and differences between these two guidelines and provide a narrative to help guide health care providers through the complexities of non-surgical management of knee OA. OARSI and ESCEO both recommended education, structured exercise and weight loss as core treatments, topical NSAIDs as first-line treatments and oral NSAIDs and intra-articular injections for persistent pain. Low-dose, short-term acetaminophen, pharmaceutical-grade glucosamine and chondroitin sulfate are recommended by ESCEO whereas OARSI strongly recommend against their use (including all glucosamine and chondroitin formulations). Despite this, the two guidelines are consistent in the majority of their recommendations and provide useful treatment recommendations for individuals with $O A$ and healthcare providers.
\end{abstract}

\title{
[H1] Introduction
}

Osteoarthritis (OA) is the most common chronic joint disorder, is characterized by local inflammation and joint structural change, and is associated with painful symptoms and loss of function leading to considerable impairment of quality of life ${ }^{(1)}$. Globally, hip and knee OA are leading contributors to disability in terms of years lived with disability ${ }^{(1,2)}$. With population ageing and rising obesity across the globe, it is widely accepted that the burden of OA will continue to increase ${ }^{(3)}$, leading to an increased strain on health care systems. Given the current absence of effective disease-modifying treatments for knee $O A$, attention has turned to providing effective guidance on the medical management of OA; over the past decade, several sets of recommendations have been published ${ }^{(4-9)}$. Clinical practice guidelines help assist decision-making and are therefore a vital source of information for health care providers.

Recommendations for OA treatment are often separated into non-pharmacological, pharmacological and surgical interventions ${ }^{(10,11)}$, as well as categorized by disease severity and joint site. Other variances in treatment guidelines include the target readership (for example, some taking a more patient-centred approach) and geographical focus (international versus national). These differences have led to some confusion, evidenced by the limited uptake of published guidelines by patients ${ }^{(12)}$ and within primary and secondary care ${ }^{(13,14)}$.

Most guidelines, however, agree in their core treatment recommendations for knee $\mathrm{OA}^{(15)}$, which include the provision of education, physical therapy and encouraging weight loss. The guidelines then typically either outline a sequential, staged approach to the management of knee OA beyond core treatments ${ }^{(6,16,17)}$ or outline treatment recommendations by disease and/or comorbidity group ${ }^{(4,7,9)}$. Treatment typically includes the use of analgesics, including non-steroidal anti-inflammatory drugs (NSAIDs) and intra-articular corticosteroid injections, with joint replacement surgery recommended for more severe cases. Whilst knee joint replacement has been shown to be effective in the management of knee OA symptoms ${ }^{(18)}$, this surgery might not be suitable for all patients as up to $20 \%$ report dissatisfaction and/or persistent symptoms post-operatively ${ }^{(19,20)}$. Furthermore, knee replacement is conventionally performed in end-stage disease ${ }^{(18)}$, after years of painful symptoms and loss of function and despite correctly conducted medical treatment.

In 2014, the European Society for Clinical and Economic Aspects of Osteoporosis, Osteoarthritis and Musculoskeletal Diseases (ESCEO) published recommendations for the management of knee OA, 
which summarized expert opinion and the most relevant, high-quality data ${ }^{(6)}$ and outlined a staged treatment algorithm to help assist health care providers in prioritizing treatments ${ }^{(6)}$. Similarly, the Osteoarthritis Research Society International (OARSI), which has a history of publishing highly cited guidelines for OA ${ }^{(21-23)}$, published recommendations in 2014 that also outlined an algorithm for the non-surgical management of knee $\mathrm{OA}^{(4)}$. In 2019, both of these international organizations updated their recommendations for the non-surgical management of knee $O A^{(16,17)}$. In November 2019, a working group comprising selected authors of the 2019 OARSI (N.K.A, R.R.B., I.K.H., T.E.M.) and ESCEO (N.K.A., O.B., C.C., J.-Y.R.) publications as well as independent members (T.A.P., M.C.H., A.M.) convened and jointly reviewed these latest guidelines. In this Perspectives article, the members of that working group highlight the similarities and differences between the treatment algorithms and the methodological approaches used to formulate recommendations in the OARSI and ESCEO guidelines.

\section{[H1] Comparison of aims and objectives}

The membership of OARSI, an international not-for-profit research society, comprises both health care professionals and researchers focused on the prevention and treatment of OA. OARSI supports the international growth of OA-related research leading to the dissemination of expert resources and knowledge. ESCEO, a not-for-profit organization that operates within Europe, specializes in the provision of care and musculoskeletal research through supporting networks between academic scientists, prescribing physicians, not-for-profit organizations, regulatory authorities and corporate partners; ESCEO is tasked with providing practitioners with the most current, clinical, and economic evidence-based information to assist in the delivery of care. Both the 2019 OARSI and ESCEO guidelines were constructed to provide a practical algorithm to help guide clinicians in their decisionmaking for the management of knee $O A^{(16,17)}$. In addition, both guidelines aimed to deliver patientcentred recommendations.

The OARSI guidelines ${ }^{(17)}$ update and expand upon previously reported OARSI guidelines ${ }^{(4)}$. Similarly, the 2019 ESCEO guidelines ${ }^{(16)}$ sought to update their previously published algorithm ${ }^{(6)}$ by including new evidence published since 2014. Whereas the 2019 ESCEO guidelines focus only on the evaluation of treatments for knee OA, the OARSI guidelines include recommendations for knee OA, hip OA and polyarticular OA. Furthermore, OARSI exclusively formulated recommendations for the non-surgical management of knee OA whereas ESCEO developed recommendations for both non-surgical and surgical treatments. For the purposes of this article, we focus exclusively on guidelines related to the non-surgical management of knee $\mathrm{OA}$ as it is generally regarded that surgical intervention remains the most effective and cost-effective treatment modality for end-stage disease ${ }^{(18,24,25)}$.

\section{[H1] Comparison of the methodologies}

In this section, we examine the similarities and differences between the methods used by OARSI and ESCEO to develop the treatment algorithms and recommendations in their respective 2019 guidelines. Briefly, the methods used were largely similar, with both organizations using well-characterized procedures for the reporting of the guidelines. However, key differences exist in the constitution of the panels, literature search strategies, voting procedures and scaling of the treatment recommendations, which need to be carefully considered. The methodological similarities and differences are summarized in Table 1. 


\section{[H2] Assessing quality of evidence}

The working groups that developed the 2019 OARSI and ESCEO guidelines both followed the Grading of Recommendations, Assessment, Development and Evaluations (GRADE) ${ }^{(26)}$ methodology, which combines an objective review of the literature with expert consensus. OARSI evaluated methodological rigor of meta-analyses and systematic reviews using the Assessment of Multiple Systematic Reviews Tool and RCTs using The Cochrane Risk of Bias Assessment method. Although several systems exist for the grading of clinical evidence and the creation of clinical practice guidelines $^{(27)}$, GRADE has been widely used owing to its balance between simplicity and its effectiveness for quality assessment ${ }^{(28,29)}$. A major difference in the development of the OARSI and ESCEO recommendations is that the OARSI working group performed new meta-analyses to inform their GRADE assessments, whereas ESCEO used published meta-analyses. For the ESCEO guidelines, the findings of network meta-analyses were assessed using GRADE only if "direct comparisons" were performed $^{(16)}$; the results from all remaining network meta-analyses were reported descriptively.

\section{[H2] Selection of the expert panels}

In their 2019 reports ${ }^{(16,17)}$, both OARSI and ESCEO recognize the need for input from multiple disciplines; thus, health care providers and patient representatives contributed to the development of the respective treatment guidelines. The structure and the duties of the panels, however, differed. Firstly, the ESCEO working group comprised European members only whereas the OARSI panels included members from the UK, Europe, Asia, North America, South America and Australasia.

ESCEO gathered a single panel of 18 members comprising specialists in rheumatology, rehabilitation, orthopaedics, clinical epidemiology, public health and health economics, as well as patient representatives, to oversee all aspects of the project; four individuals were tasked with conducting the literature search. By contrast, OARSI recruited a core expert panel of six members who supervised the project; a separate voting panel consisted of 13 members considered representative of the wider OARSI membership, including specialists in rheumatology, orthopaedics, primary care, pharmacology, sports medicine, physical therapy and rehabilitation. In addition, a literature review team comprised five individuals with methodological expertise, and a patient panel comprised three patient representatives who were invited to participate in formulating the OARSI recommendations during a meeting at the 2018 OARSI convention. A key difference between the task forces was that the OARSI literature review panel pre-selected specialists in statistical methods whereas the ESCEO panel did not; this difference is most likely attributable to the fact that OARSI conducted new meta-analyses as part of the assessment process whilst the ESCEO assessment was restricted to a systematic review.

\section{[H2] Declaring competing interests (COI)}

For OARSI, conflicts of interests were managed by adherence to OARSI Ethics Committee guidelines and by independent review of disclosures by the Ethics Committee. Individuals with high-level COI (e.g. close involvement with a manufacturer of a product) were ineligible, while those with lower level related to a specific intervention (e.g. consulting) were prohibited from participating in discussions, evidence synthesis, and/or review of the corresponding sections ${ }^{(17)}$. By contrast, ESCEO permitted panel members to participate provided they were transparent regarding any potential conflicts of interest. 


\section{[H2] Literature searches}

Both the OARSI and ESCEO panels conducted extensive systematic reviews and adhered to a predefined consensus methodology to develop their recommendations. Both systematic searches identified systematic reviews, meta-analysis and relevant randomized-controlled trials. However, the review methodologies differed in some respects.

A key difference between the OARSI and ESCEO literature search strategies was that the OARSI core expert panel developed a list of a priori questions formulated using the PICO (population, intervention, control and outcomes) framework before commencement of the systematic search. The PICO question list consisted of 67 knee OA-related questions focused on evaluating the benefits and harms of 31 non-pharmacological, 24 pharmacological and 12 nutraceutical treatments. The ESCEO panel did not adopt PICO methodology prior to conducting their systematic search, but rather focused on the evaluation of a select number of treatments in specific, patient-centred scenarios. Using the PICO framework to inform the systematic literature search was a key advantage of the OARSI guidelines methodology, as the development of focused clinical questions, modelled using the PICO framework, is considered the most effective approach to identifying high-quality evidence ${ }^{(30)}$ with data from empirical studies suggesting this approach yields more precise search results ${ }^{(31)}$. Furthermore, the use of PICO questions to evaluate the benefits and harms of non-surgical treatments for knee OA helped to ensure that the search strategy was patient-focused.

The OARSI and ESCEO searches identified relevant manuscripts in the Medline, EMBASE and Cochrane databases; the OARSI search also included PubMed, Google Scholar and the reference lists of systematic reviews and meta-analyses. The ESCEO panel performed a systematic literature search for publications from 2014 through to September 30, 2018 using a combination of keywords and controlled search terms ${ }^{(16)}$; the specific terms used in the search strategy were not published by ESCEO. The aim was to identify the most relevant literature related to treatments listed in the previous 2014 guidelines $^{(6)}$ and any other interventions subsequently approved or available for the management of knee $O A^{(16)}$. The OARSI literature review panel searched the aforementioned databases using search terms such as "osteoarthritis", "arthrosis", "trial", "comparative study", "arthroplasty" and "single/double-blind", with no start date specified. In the first instance, a PICOinformed systematic review of the literature from inception to December 2017 was performed and was later updated on July $12,2018^{(17)}$. By specifying the inclusion of 'approved' medications, the search strategy employed by the ESCEO panel could have yielded fewer publications than the OARSI strategy. More importantly, this restriction might have excluded informative data; for instance, data from phase 0 -III trials in knee $O A$ in which the medication under investigation had not yet been approved by the US Food and Drug Administration (FDA) or the European Medicines Agency (EMA).

Both the OARSI and ESCEO teams screened the abstracts and full texts of the identified publications. When relevant data were available, both the ESCEO and OARSI teams performed 'quality of literature' assessment using the GRADE criteria to assign literature a score of high, moderate, low or very low.

\section{[H2] Voting procedures}

As part of the OARSI methodology, prior to panel voting, the core expert panel reviewed all relevant documentation synthesized from the systematic literature search and GRADE evidence tables for each intervention. Once this review was completed, the dedicated voting panel, which had access to all the supplementary background materials (including primary data, analyses and GRADE tables), voted on the recommendations formed to address the PICO questions. All voting on recommendations was 
done using an online, electronic system (http://www.surveymonkey.com) with all votes kept completely anonymous. All contentious issues were discussed and debated in an online discussion forum before being subjected to re-voting. By contrast, all members of the ESCEO working group were provided with more detailed work packages, which included details of the 2014 algorithm, selected detailed summaries of the results of the updated literature search (2014-2018), GRADE evidence tables that included summaries of the quality of the evidence, and details of the magnitude of the effect for each respective intervention; reference lists were also provided. Voting by the ESCEO working group was completed anonymously via email with panellists voting on their recommendation for each respective intervention.

Both the OARSI and ESCEO working groups invited their voting panels to provide a recommendation for each question and/or intervention, as outlined in Figure 1 . Votes by the panels were cast on the direction and strength of the recommendations. For the ESCEO guidelines, all treatment recommendations were assessed according to the following criteria: current and past evidence; balance between the benefits and harms of each intervention; magnitude of treatment effects; quality of the evidence; value and preferences; costs (informed by clinical experience and formal cost assessments); and the position of an intervention within the treatment algorithm ${ }^{(16)}$. Similarly, the OARSI recommendations were based on modified GRADE criteria, which included the criteria listed above as well as the assessment of estimates of treatment effect size, confidence in such estimates and clinical preference. Unlike the ESCEO working group, the OARSI panel conducted a two-stage vote. In the first stage, the expert panel voted on the inclusion or exclusion of a select few interventions that were put forward by the expert panel; interventions that remained after the first stage were termed 'core treatments', defined as those appropriate for use in almost all patients and safe to use in combination with first-line and second-line treatments. In the second stage, which consisted of three voting rounds, all remaining interventions (including those that were excluded in the first stage) were voted on. The voting panel were asked to vote on the directionality ('in favour' or 'against') and strength ('strong' or 'conditional') of their recommendation in line with modified GRADE criteria.

One of the key differences between the ESCEO and OARSI recommendations was that OARSI specified that in the event that no adequate evidence could be found for a specified intervention, the evidence quality score for that given intervention was designated as 'very low' by default ${ }^{(17)}$. In the event that the ESCEO panel members thought the available evidence was balanced (that is, between 'do' and do not'), they could vote 'no recommendation'. Of the 14 non-surgical recommendations proposed by ESCEO, 5 are 'strong' and 9 are 'weak'; the OARSI panel made 9 'strong' recommendations (core treatments and topical NSAIDs) and 13 'conditional' recommendations. Only core treatments and level $1 \mathrm{~A}$ and level 5 recommendations made by OARSI are 'strong' whereas all remaining recommendations are 'conditional' (see FIG. 1).

\section{[H1] Comparison of the recommendations}

We have discussed the similarities and the differences in methods used in the development of the 2019 OARSI and ESCEO recommendations. Despite such differences, the joint OARSI-ESCEO working group found, as outlined in this section, that many aspects of the recommendations for the nonsurgical management of knee $O A$ are in agreement. 


\section{[H2] Similarities}

\section{[H3] Core treatments appropriate for use in the majority of patients.}

In both the OARSI and ESCEO stepwise treatment algorithms, patient education and/or access to information, exercise and weight loss (if a patient is overweight) should form the core treatment approach prior to the commencement of first-line and stage 2 treatments (as shown in Figure 2) ${ }^{(16,17)}$. In line with their 2014 recommendations ${ }^{(6)}$, the 2019 ESCEO recommendations endorse aerobic, strengthening and resistance exercises. Similarly, the OARSI guidelines recommend structured, landbased exercise programmes of strengthening, cardiovascular, balance and/or neuromuscular exercises, but also add mind-body exercise including Tai Chi and yoga. The only subtle difference between the two guidelines is that the ESCEO recommendation includes all types of exercise, stating that the evidence to differentiate between different modalities is not available, whereas the OARSI recommendation excludes aquatic exercise from core treatments owing to concerns about accessibility.

\section{[H3] First-line treatments.}

Following core treatment(s), both the OARSI and ESCEO guidelines strongly recommend the use of topical NSAIDs in the first-line management of knee OA, owing to their proven efficacy and a low risk of gastrointestinal, cardiovascular and renal adverse effects ${ }^{(16,17)}$. Both guidelines advise against the long-term use of paracetamol (acetaminophen) as a first-line treatment for knee OA, with the OARSI guidelines strongly recommending against its use in both the short term and long term, and the ESCEO guidelines making a 'weak' recommendation for its use in the short term. Both guidelines do not recommend the use of supplementation with non-pharmaceutical grade glucosamine hydrochloride, glucosamine sulfate and/or chondroitin sulfate.

\section{[H3] Pharmacological management of persistent symptoms.}

As a stage 2 therapy, both the OARSI and ESCEO guidelines recommend the use of oral NSAIDs in patients with persistent $O A$ symptoms after the use of first-line treatments, personalized according to a patient's gastrointestinal and cardiovascular risk profile ${ }^{(16,17)}$. Both set of guidelines are in agreement that oral NSAIDs should only be used intermittently for the shortest period of time and at the lowest possible dose to control pain, owing to their known adverse cardiovascular, hepatic and renal effects. Specifically, for patients with normal gastrointestinal function both sets of guidelines recommend the use of non-selective oral NSAIDs, preferably in combination with a proton pump inhibitor (PPI), or selective COX-2 inhibitors. In those with gastrointestinal complications, selective COX-2 inhibitors and non-selective NSAIDs in combination with a PPI are recommended by both sets of guidelines with the ESCEO guidelines further suggesting that celecoxib may be the 'preferred' oral NSAID ${ }^{(16)}$. In those with an increased risk of cardiovascular events, both the ESCEO and OARSI guidelines are very cautious: the former suggests limiting the use of COX-2 inhibitors to 30 days and of non-selective NSAIDs to 7 days, whereas the latter recommends against use of any oral NSAIDs in this group of patients. In the OARSI guidelines NSAIDs are not recommended for use in patients with frailty; the ESCEO guidelines make no such recommendation as this comorbidity was not assessed. Age is a major risk factor in its own right for cardiovascular, cerebrovascular and gastrointestinal adverse outcomes and should be taken into account when assessing the benefit:risk ratio of NSAID usage ${ }^{(32,33)}$. There is also evidence to suggest that age increases the relative risk of adverse effects of NSAIDs, thus it has been 
recommended that oral NSAIDs should not be used in persons aged 65 and above ${ }^{(34)}$. The ESCEO guidelines recommend the use of topical NSAIDs over oral NSAIDs for patients with OA aged $\geq 75$ years and for those at increased risk of renal adverse events; the OARSI guidelines make no such recommendation because this age group was not considered separately.

Both the OARSI and ESCEO guidelines support the use intra-articular injections of corticosteroids and state that this intervention might be more effective in the short-term ( 2-4 weeks) than in the longterm ( $\geq 6$ weeks) ${ }^{(16,17)}$. Specifically, the ESCEO guidelines recommend the use of intra-articular corticosteroids in patients with persistent pain after first-line treatments and oral NSAIDs, suggesting that this approach is more effective in those with more severe pain, which might be a predictor of its short-term efficacy. Similarly, the OARSI guidelines recommend use of intra-articular corticosteroids in patients who fail to achieve symptom relief after treatment with core treatments, topical NSAIDs and/or non-selective NSAIDs. Neither the OARSI nor ESCEO guidelines recommend the use of the presence of effusion as a predictor of a positive response to intra-articular corticosteroids. Intraarticular hyaluronic acid is recommended in both guidelines. The OARSI guidelines conditionally recommended IAHA for all patients at different stages of treatment depending on their comorbidity profiles. For example, in patients with knee OA who have no comorbidities, IAHA is recommended after failure to respond to core treatments, topical NSAIDs and oral NSAIDs (including COX-2 inhibitors). The ESCEO guidelines recommend use of IAHA in patients with contraindications to NSAIDs or those who are still symptomatic despite use of NSAIDs.

\section{[H2] Differences}

The OARSI and ESCEO treatment algorithms differ in several ways, as summarized in Table 2. In this section, we expand upon the differences in recommendations beyond core treatments.

\section{[H3] First-line treatment(s).}

The ESCEO recommendations advise that patients should be referred to a physical therapist or other medical professional to determine if varus or valgus correction is needed following adherence to core treatments ${ }^{(16)}$. Alternatively, the OARSI guidelines recommend an initial physical assessment prior to entry into the treatment algorithm. As part of first-line treatment, the ESCEO and OARSI guidelines both recommend the use of topical NSAIDs. OARSI recommends their use as the first pharmacologic intervention in all patients except those with chronic widespread pain disorder. The ESCEO guidelines, however, recommend topical NSAID use if painful symptoms persist following short-term rescue analgesia with paracetamol (at doses of no greater than $3 \mathrm{~g}$ per day), treatment with symptomatic slow-acting drugs for OA (SYSADOAs) which include pharmaceutical-grade (microcrystalline) glucosamine sulfate and chondroitin sulfate and, physical therapy. Background therapy with these products is recommended by ESCEO prior to the use of topical NSAIDs based on their interpretation of the evidence base ${ }^{(16,35-38)}$, and likely because of the inferred excellent safety profile of SYSADOAS and long lasting symptomatic effects. OARSI evaluated the same literature base and made negative recommendations for all glucosamine and chondroitin products (including pharmaceutical-grade).

The ESCEO guidelines provide recommendations for the use of SYSADOAs, including strong recommendations for pharmaceutical-grade crystalline glucosamine sulfate and chondroitin sulfate and weak recommendations for avocado soybean unsaponifiables and diacerein; they also make a weak recommendation against the use of combined glucosamine and chondroitin sulfate. Another 
difference between the ESCEO and OARSI recommendations is that the former made separate recommendations for pharmaceutical-grade and non-pharmaceutical grade whereas OARSI's recommendations are generalizable to all such products. ESCEO generated negative recommendations for non-pharmaceutical grade glucosamine and chondroitin formulations whilst OARSI made strong recommendations against the use of all formulations (including pharmaceuticalgrade) because of a lack of efficacy or low quality evidence and high risk of bias ${ }^{(16,17)}$.

\section{[H3] Final pharmacological treatment before surgery.}

As the last attempt to manage symptoms pharmacologically before surgical intervention, the ESCEO guidelines recommend the short-term use of weak opioids (such as tramadol) because of their efficacy in relieving pain and providing small improvements in function. However, the adverse effects of these drugs, which include drowsiness, dizziness, nausea, constipation and an increase in the risk of falls (especially in elderly patients) are well known; hence, they should be used only for short periods of time. As an alternative to opioids, the ESCEO guidelines further recommend the use of duloxetine (a serotonin-norepinephrine reuptake inhibitor, particularly in patients with central pain sensitization, despite an increased risk of adverse events including dizziness and risk of falls. The OARSI guidelines, however, make negative recommendation for the use of opioids owing to their unfavourable efficacy and/or safety profile ${ }^{(17)}$, and recommend duloxetine only for patients who have knee OA and widespread pain and/or depression.

\section{[H3] Consideration of comorbidities.}

Both the OARSI and ESCEO 2019 guidelines tailor their treatment recommendations to specific comorbidities. Specifically, both include treatment recommendations for patients with knee OA who have no comorbidities and those with or at an increased risk of adverse gastrointestinal and cardiovascular outcomes. In addition, the OARSI recommendations are tailored for patients with frailty or widespread pain and/or depression; the ESCEO recommendations are not, although they are tailored to those at an increased risk of renal adverse events. The OARSI working group set out to evaluate treatments in the context of comorbidities a priori and the treatment recommendations were informed by the systematic literature searches, whereas it was unclear from the ESCEO manuscript whether making recommendations in the context of comorbidities was a primary or secondary objective. In addition, a key difference between the two sets of guidelines is that the OARSI guidelines include "Good Clinical Practice Statements" to accompany the recommendations, which were written to help support the treatment recommendations and were informed by expert experience.

\section{[H1] Implications and perspectives}

The 2019 recommendations proposed by OARSI and ESCEO outline two informative treatment algorithms for the non-surgical management of knee OA. Both sets of recommendations provide health care providers with evidence-based and expert-reviewed advice. Overall, the two publications provide very similar recommendations, particularly with regard to the core treatments that all patients should receive. They both provide similar, progressive management algorithms, although some differences exist, particularly in the ordering of treatments along the treatment algorithm. Both attempt to 'personalize' the treatment algorithms to patient characteristics, which is essential when 
considering the use of oral NSAIDs and COX-2 selective inhibitors. Specifically, the OARSI recommendations are tailored for groups with particular comorbidities including those at an increased risk of gastrointestinal or cardiovascular adverse events, those with frailty and those with widespread pain and/or depression. The ESCEO recommendations are personalized by considerations for gastrointestinal, cardiovascular, hepatic and renal risk and for specific age groups. Neither set of recommendations specifically discussed age as a factor by which to personalize treatment; however, it is likely that the consideration of co-morbidities, especially frailty, partially take age into account.

The OARSI and ESCEO guidelines differ in their recommendations for the use of topical NSAIDs and SYSADOAs. ESCEO recommends the use of pharmaceutical-grade glucosamine and chondroitin sulfate as first-line therapies prior to the use of topical NSAIDs in those with persistent symptoms. OARSI, however, strongly recommends against the use of all glucosamine and chondroitin formulations (including pharmaceutical-grade); OARSI recommends the use of topical NSAIDS as the first line treatment. A possible explanation for the conflicting recommendations made by the ESCEO and OARSI groups regarding the use of glucosamine are most likely attributable to differences in the interpretation of the quality of the evidence, including risk of bias, and in the synthesis of that evidence by the expert panels. Lastly, both sets of recommendations strongly advise against the long-term use of paracetamol owing to its low efficacy and notable adverse effect profile; however, the ESCEO guidelines do suggest short-term use of doses limited to $3 \mathrm{~g}$ per day. Again, the assessment of different study literature could explain this difference. Specifically, in their updated literature search (20142018) the ESCEO panel evaluated 4 reviews and/or meta-analyses that examined the safety and efficacy of paracetamol, which covered both randomized trials and observational studies, whereas the OARSI panel examined only the results of 5 randomized trials. The ESCEO panel reported that whilst they found no evidence for the use of paracetamol in the short-term as a rescue analgesic on a background of other treatments (for example, SYSADOAs), they comment that "this is its traditional use" (16). Consequently, the recommendation for the short-term use of paracetamol might be informed moreso by clinical opinion than by the clinical evidence.

The differences in the treatment recommendations proposed by the OARSI and ESCEO working groups can be explained, in part, by methodological differences. Despite evaluating similar data, both groups made several different treatment recommendations, which would suggest that a degree of uncertainty regarding the available evidence remains. Hence, there is a need for more robust evidence.

\section{[H1] Conclusions}

Overall, the 2019 OARSI and ESCEO treatment algorithms for the non-surgical management of knee OA overlap considerably, which should provide practising clinicians confidence and clarity regarding the treatment of patients with knee OA. The differences between the two sets of recommendations might be attributable, in part, to methodological issues, highlighting the importance of refining and harmonizing guideline methodology and ideally producing unified guidelines that are endorsed by multiple societies and non-governmental organizations. Furthermore, harmonization could be achieved through the encouragement of cross-collaboration between both national and international organizations. Practising clinicians would also benefit from the future development of online educational programmes specifically designed for health care practitioners with input from all the major societies and stakeholders, with the subsequent distillation of a consistent set of recommendations for patients with $\mathrm{OA}$ and the lay public. 


\section{Competing interests statement}

N.K.A. declares that he has received grants and personal fees from Merck, and personal fees from Flexion, Regeneron, Pfizer, and Eli Lilly. R.R.B. is supported by the NIH National Center for Complementary and Integrative Health (K23AT009374). O.B. declares that he has received grants from Biophytis, IBSA, MEDA, Servier, SMB and Theramex. C.C. declares that he has received lecture fees and honoraria from Amgen, Danone, Eli Lilly, GSK, Kyowa Kirin, Medtronic, Merck, Nestlé, Novartis, Pfizer, Roche, Servier, Shire, Takeda and UCB, outside of the submitted work. I.K.H. declares that she has received honoraria from Abbvie and a research grant from Pfizer, outside of the submitted work. M.H. declares that he has acted as a consultant, including attending at Advisory Board meetings, for Bone Therapeutics, Bristol Myers Squibb, Eli Lilly, EMD Serono, Gilead, GlaxoSmithKline, IBSA Institut Biochimique SA, Novartis Pharma AG, Noven Pharmaceuticals, Pfizer, Regenosine, Samumed LLC, Theralogix LLC and Vizuri Health Sciences, and that he has received royalties from Elsevier (for his roles as Editor of Rheumatology and Editor-in-Chief of Seminars in Arthritis and Rheumatism) and Wolters Kluwer (UpToDate ${ }^{\mathrm{TM}}$ ) outside of the submitted work. T.E.M. declares that he has acted as a consultant for Samumed, Kolon TissueGene, Pfizer, Sanofi, Regeneron, Noven, Remedium-Bio. A.M. declares that he has acted as a consultant for Abbvie, Aché (Aché Laboratórios Farmacêuticos), Artialis SA, Flexion Therapeutics, Galapagos, Genacol, GSK Consumer Healthcare, IAG, Kolon TissueGene, Pfizer, Pfizer Consumer Healthcare, Servier, Sterifarma, Sanofi and Pacira Biosciences, received research funding from the European Commission (FP7, IMI, Marie Skłodowska-Curie, ES Struktūrinės Paramos), Versus Arthritis (formerly Arthritis Research UK) and initiated research contracts with Merck KGaA and Kolon TissueGene and received speakers' fees from Bioiberica SA, the Korean Society for Osteoarthritis and Cartilage Repair, the American College of Rheumatology, the Spanish Society of Rheumatology, the Heilongjiang Rheumatology Association and the Zhujiang Hospital of Southern Medical University. J.Y.R. declares that he has received grants and personal fees from IBSA-Genevrier, Mylan, and Radius Health, grants from CNIEL, and personal fees from Dairy Research Council and Pierre Fabre, outside of the submitted work. The other authors declare no conflicts of interest.

\section{Acknowledgements}

Authors' statement: The diverse views and opinions expressed in this article represent the outcomes of a joint working group, consisting of current members of the Osteoarthritis Research Society International (OARSI) and European Society for Clinical and Economic Aspects of Osteoporosis, Osteoarthritis and Musculoskeletal Diseases (ESCEO), which examined the similarities and differences in the 2019 OARSI and ESCEO guidelines for the management of knee OA. The working group was entirely funded by ESCEO. To support its educational and scientific activities, ESCEO receives unrestricted educational grants from non-governmental organizations, not-for-profit organizations, non-commercial and corporate partners. The choice of topics, participants, content and agenda of the working group, as well as the writing, editing, submission and reviewing of the manuscript are the sole responsibility of ESCEO, without any influence from third parties. ESCEO is supported by the Chair for Biomarkers of Chronic Diseases and the International Scientific Partnership Program (ISPP\#0111) at King Saud University, Riyadh, Saudi Arabia.

\section{Author contributions}

T.A.P., N.K.A., R.R.B. and O.B. researched data for the article. T.AP. and N.K.A. wrote the manuscript. All authors made a substantial contribution to discussion of content and review/editing of the manuscript before submission. 


\section{References}

1. Safiri S, Kolahi A-A, Smith E, Hill C, Bettampadi D, Mansournia MA, et al. Global, regional and national burden of osteoarthritis 1990-2017: a systematic analysis of the Global Burden of Disease Study 2017. Ann Rheum Dis. 2020;79(6):819-28.

2. Disease GBD, Injury I, Prevalence C, James SL, Abate D, Abate KH, et al. Global, regional, and national incidence, prevalence, and years lived with disability for 354 diseases and injuries for 195 countries and territories, 1990-2017: a systematic analysis for the Global Burden of Disease Study 2017. Lancet. 2018;392(10159):1789-858.

3. Culliford D, Maskell J, Judge A, Cooper C, Prieto-Alhambra D, Arden NK, et al. Future projections of total hip and knee arthroplasty in the UK: results from the UK Clinical Practice Research Datalink. Osteoarthritis Cartilage. 2015;23(4):594-600.

4. McAlindon TE, Bannuru RR, Sullivan MC, Arden NK, Berenbaum F, Bierma-Zeinstra SM, et al. OARSI guidelines for the non-surgical management of knee osteoarthritis. Osteoarthritis Cartilage. 2014;22(3):363-88.

5. Jordan KM, Arden NK, Doherty M, Bannwarth B, Bijlsma JWJ, Dieppe P, et al. EULAR Recommendations 2003: an evidence based approach to the management of knee osteoarthritis: Report of a Task Force of the Standing Committee for International Clinical Studies Including Therapeutic Trials (ESCISIT). Ann Rheum Dis. 2003;62(12):1145-55.

6. Bruyere O, Cooper C, Pelletier J-P, Branco J, Luisa Brandi M, Guillemin F, et al. An algorithm recommendation for the management of knee osteoarthritis in Europe and internationally: a report from a task force of the European Society for Clinical and Economic Aspects of Osteoporosis and Osteoarthritis (ESCEO). Semin Arthritis Rheum. 2014;44(3):253-63.

7. Hochberg MC, Altman RD, April KT, Benkhalti M, Guyatt G, McGowan J, et al. American College of Rheumatology 2012 recommendations for the use of nonpharmacologic and pharmacologic therapies in osteoarthritis of the hand, hip, and knee. Arthritis Care Res (Hoboken). 2012;64(4):465-74.

8. Jevsevar DS, Brown GA, Jones DL, Matzkin EG, Manner PA, Mooar P, et al. The American Academy of Orthopaedic Surgeons evidence-based guideline on: treatment of osteoarthritis of the knee, 2nd edition. J Bone Joint Surg Am. 2013;95(20):1885-6.

9. Kolasinski SL, Neogi T, Hochberg MC, Oatis C, Guyatt G, Block J, Callahan L, Copenhaver C, Dodge C, Felson D, Gellar K, Harvey WF, Hawker G, Herzig E, Kwoh CK, Nelson AE, Samuels J, Scanzello C, White D, Wise B, Altman RD, DiRenzo D, Fontanarosa J, Giradi G, Ishimori M, Misra D, Shah AA, Shmagel AK, Thoma LM, Turgunbaev M, Turner AS, Reston J. 2019 American College of Rheumatology/Arthritis Foundation Guideline for the Management of Osteoarthritis of the Hand, Hip, and Knee. Arthritis Rheumatol. 2020 Feb;72(2):220-233. doi: 10.1002/art.41142. Epub 2020 Jan 6. PMID: 31908163.

10. Bijlsma JWJ, Berenbaum F, Lafeber FPJG. Osteoarthritis: an update with relevance for clinical practice. Lancet. 2011;377(9783):2115-26.

11. Buttgereit F, Burmester G-R, Bijlsma JWJ. Non-surgical management of knee osteoarthritis: where are we now and where do we need to go? RMD Open. 2015;1(1):e000027.

12. Healey EL, Afolabi EK, Lewis M, Edwards JJ, Jordan KP, Finney A, et al. Uptake of the NICE osteoarthritis guidelines in primary care: a survey of older adults with joint pain. BMC Musculoskelet Disord. 2018;19(1):295.

13. Carlson VR, Ong AC, Orozco FR, Hernandez VH, Lutz RW, Post ZD. Compliance With the AAOS Guidelines for Treatment of Osteoarthritis of the Knee: A Survey of the American Association of Hip and Knee Surgeons. J Am Acad Orthop Surg. 2018;26(3):103-7.

14. Basedow M, Williams $H$, Shanahan EM, Runciman WB, Esterman A. Australian GP management of osteoarthritis following the release of the RACGP guideline for the non-surgical management of hip and knee osteoarthritis. BMC Res Notes. 2015;8:536.

15. Nelson AE, Allen KD, Golightly YM, Goode AP, Jordan JM. A systematic review of recommendations and guidelines for the management of osteoarthritis: The chronic 
osteoarthritis management initiative of the U.S. bone and joint initiative. Semin Arthritis Rheum. 2014;43(6):701-12.

16. Bruyere O, Honvo G, Veronese N, Arden NK, Branco J, Curtis EM, et al. An updated algorithm recommendation for the management of knee osteoarthritis from the European Society for Clinical and Economic Aspects of Osteoporosis, Osteoarthritis and Musculoskeletal Diseases (ESCEO). Semin Arthritis Rheum. 2019;49(3):337-50.

17. Bannuru RR, Osani MC, Vaysbrot EE, Arden NK, Bennell K, Bierma-Zeinstra SMA, et al. OARSI guidelines for the non-surgical management of knee, hip, and polyarticular osteoarthritis. Osteoarthritis Cartilage. 2019;27(11):1578-89.

18. Price AJ, Alvand A, Troelsen A, Katz JN, Hooper G, Gray A, et al. Knee replacement. Lancet. 2018;392(10158):1672-82.

19. Dieppe P, Lim K, Lohmander S. Who should have knee joint replacement surgery for osteoarthritis? Int J Rheum Dis. 2011;14(2):175-80.

20. Beswick AD, Wylde V, Gooberman-Hill R, Blom A, Dieppe P. What proportion of patients report long-term pain after total hip or knee replacement for osteoarthritis? A systematic review of prospective studies in unselected patients. BMJ Open. 2012;2(1):e000435.

21. Zhang W, Moskowitz RW, Nuki G, Abramson S, Altman RD, Arden N, et al. OARSI recommendations for the management of hip and knee osteoarthritis, part I: critical appraisal of existing treatment guidelines and systematic review of current research evidence. Osteoarthritis Cartilage. 2007;15(9):981-1000.

22. Zhang W, Moskowitz RW, Nuki G, Abramson S, Altman RD, Arden N, et al. OARSI recommendations for the management of hip and knee osteoarthritis, Part II: OARSI evidencebased, expert consensus guidelines. Osteoarthritis Cartilage. 2008;16(2):137-62.

23. Zhang W, Nuki G, Moskowitz RW, Abramson S, Altman RD, Arden NK, et al. OARSI recommendations for the management of hip and knee osteoarthritis: part III: Changes in evidence following systematic cumulative update of research published through January 2009. Osteoarthritis Cartilage. 2010;18(4):476-99.

24. Lutzner J, Kasten P, Gunther K-P, Kirschner S. Surgical options for patients with osteoarthritis of the knee. Nat Rev Rheumatol. 2009;5(6):309-16.

25. Beard DJ, Davies LJ, Cook JA, MacLennan G, Price A, Kent S, et al. The clinical and costeffectiveness of total versus partial knee replacement in patients with medial compartment osteoarthritis (TOPKAT): 5-year outcomes of a randomised controlled trial. Lancet. 2019;394(10200):746-56.

26. Guyatt GH, Oxman AD, Vist GE, Kunz R, Falck-Ytter $Y$, Alonso-Coello P, et al. GRADE: an emerging consensus on rating quality of evidence and strength of recommendations. Bmj. 2008;336(7650):924-6.

27. Atkins D, Eccles M, Flottorp S, Guyatt GH, Henry D, Hill S, et al. Systems for grading the quality of evidence and the strength of recommendations I: critical appraisal of existing approaches The GRADE Working Group. BMC Health Serv Res. 2004;4(1):38.

28. Atkins D, Best D, Briss PA, Eccles M, Falck-Ytter Y, Flottorp S, et al. Grading quality of evidence and strength of recommendations. Bmj. 2004;328(7454):1490.

29. Kavanagh BP. The GRADE system for rating clinical guidelines. PLoS Med. 2009;6(9):e1000094.

30. Huang X, Lin J, Demner-Fushman D. Evaluation of PICO as a knowledge representation for clinical questions. AMIA Annu Symp Proc. 2006:359-63.

31. Cheng GYT. A study of clinical questions posed by hospital clinicians. J Med Libr Assoc. 2004;92(4):445-58.

32. Sostres C, Gargallo CJ, Arroyo MT, Lanas A. Adverse effects of non-steroidal anti-inflammatory drugs (NSAIDs, aspirin and coxibs) on upper gastrointestinal tract. Best Pract Res Clin Gastroenterol. 2010;24(2):121-32.

33. Bhala N, Emberson J, Patrono C, Baigent C, Collaborators CNT. Coxibs and traditional NSAIDs for pain relief - Authors' reply. Lancet. 2014;383(9912):122. 
34. Fick DM, Semla TP, Steinman M, Beizer J, Brandt N, Dombrowski R, et al. American Geriatrics Society 2019 Updated AGS Beers Criteria (R) for Potentially Inappropriate Medication Use in Older Adults. J Am Geriatr Soc. 2019;67(4):674-94.

35. Kahan A, Uebelhart D, De Vathaire F, Delmas PD, Reginster J-Y. Long-term effects of chondroitins 4 and 6 sulfate on knee osteoarthritis: the study on osteoarthritis progression prevention, a twoyear, randomized, double-blind, placebo-controlled trial. Arthritis Rheum. 2009;60(2):524-33.

36. Zegels $B$, Crozes $P$, Uebelhart D, Bruyere $O$, Reginster JY. Equivalence of a single dose $(1200 \mathrm{mg})$ compared to a three-time a day dose $(400 \mathrm{mg})$ of chondroitin $4 \& 6$ sulfate in patients with knee osteoarthritis. Results of a randomized double blind placebo controlled study. Osteoarthritis Cartilage. 2013;21(1):22-7.

37. Schneider H, Maheu E, Cucherat M. Symptom-modifying effect of chondroitin sulfate in knee osteoarthritis: a meta-analysis of randomized placebo-controlled trials performed with structum(). Open Rheumatol J. 2012;6:183-9.

38. Reginster J-Y, Dudler J, Blicharski T, Pavelka K. Pharmaceutical-grade Chondroitin sulfate is as effective as celecoxib and superior to placebo in symptomatic knee osteoarthritis: the ChONdroitin versus CElecoxib versus Placebo Trial (CONCEPT). Ann Rheum Dis. 2017;76(9):153743. 
Table 1: Comparison of methodologies used to develop recommendations for non-surgical management of knee $O A$.

\begin{tabular}{|c|c|c|}
\hline Methods & OARSI & ESCEO \\
\hline Objectives & $\begin{array}{l}\text { To perform an updated review of the } \\
\text { literature, to assess the harms and } \\
\text { benefits of } 67 \text { pre-specified non- } \\
\text { surgical treatments for knee OA and } \\
\text { to develop a treatment algorithm for } \\
\text { the non-surgical management of } \\
\text { knee OA. }\end{array}$ & $\begin{array}{l}\text { To perform an updated review of the } \\
\text { literature, to assess the efficacy of a } \\
\text { select group of medications and to } \\
\text { develop a set of treatment } \\
\text { recommendations for the surgical } \\
\text { and non-surgical management of } \\
\text { knee OA in patient-specific scenarios. }\end{array}$ \\
\hline Panel(s) & $\begin{array}{l}\text { The OARSI working group included } \\
\text { specialists in rheumatology, } \\
\text { orthopaedics, primary care, } \\
\text { pharmacology, sports medicine, } \\
\text { clinical epidemiology, evidence- } \\
\text { based medicine, rehabilitation and } \\
\text { physical therapy, as well as patient } \\
\text { representatives. } \\
\text { A core expert panel of six members } \\
\text { supervised the project. The voting } \\
\text { panel comprised } 13 \text { members, and } \\
\text { five individuals made up the } \\
\text { literature review panel. }\end{array}$ & $\begin{array}{l}\text { The ESCEO working group included } \\
\text { specialists in rheumatology, } \\
\text { rehabilitation, orthopaedics, clinical } \\
\text { epidemiology, geriatrics, } \\
\text { pharmacology, public health and } \\
\text { health economics, as well as patient } \\
\text { representatives. } \\
\text { A single panel comprised } 18 \\
\text { members, of whom four conducted } \\
\text { the literature search. }\end{array}$ \\
\hline Literature search & $\begin{array}{l}\text { Databases searched included } \\
\text { Medline, EMBASE, Cochrane } \\
\text { databases, PubMed, Google Scholar } \\
\text { and the reference lists of relevant } \\
\text { systematic reviews and meta- } \\
\text { analyses. } \\
\text { Modified GRADE criteria were used } \\
\text { to rate the quality of evidence. } \\
\text { The literature search covered the } \\
\text { period until December } 2017 \text { (with no } \\
\text { start date); the search was updated } \\
\text { on July 12 }{ }^{\text {th }} \text { 2018. } \\
\text { Search terms included, but were not } \\
\text { limited to, "osteoarthritis", } \\
\text { "'arthrosis", "randomized controlled } \\
\text { trials", "cross-over", "controlled } \\
\text { trial", "double-blind", "single-blind", } \\
\text { "arthroscopy", 'arthroplasty'. } \\
\text { Meta-analyses of the reviewed } \\
\text { manuscripts were performed. }\end{array}$ & $\begin{array}{l}\text { Databases searched included } \\
\text { Medline, EMBASE and Cochrane } \\
\text { databases. } \\
\text { GRADE criteria were used to rate the } \\
\text { quality of evidence. } \\
\text { The literature search covered the } \\
\text { period included in the previous } \\
\text { guidelines (that is, } 2000 \text { to February } \\
2014 \text { ) plus a new search that covered } \\
\text { publications from } 2014 \text { to September } \\
30^{\text {th }} 2018 \text {. } \\
\text { Search terms included keywords and } \\
\text { controlled terms for the study types } \\
\text { and OA; the exact search strategies } \\
\text { used were not published. } \\
\text { Meta-analysis was not performed. }\end{array}$ \\
\hline
\end{tabular}




\begin{tabular}{|l|l|l|}
\hline Voting procedure & $\begin{array}{l}\text { Voting on recommendations was } \\
\text { carried out online using an } \\
\text { anonymous survey application. } \\
\text { In stage 1, the initial vote was to } \\
\text { select core treatments from a pre- } \\
\text { specified list of candidates. } \\
\text { Stage } 2 \text { consisted of three further } \\
\text { voting rounds. }\end{array}$ & $\begin{array}{l}\text { Votes were submitted by email and } \\
\text { were anonymous. The number of } \\
\text { voting rounds was not reported. }\end{array}$ \\
\hline $\begin{array}{l}\text { Strength of } \\
\text { recommendations }\end{array}$ & $\begin{array}{l}\text { Recommendations were determined } \\
\text { to be 'strong' (if } \geq 75 \% \text { of the panel } \\
\text { voted either in favour of or against) } \\
\text { or 'conditional' (if 26-74\% of the } \\
\text { panel voted for or against and vice } \\
\text { versa) }\end{array}$ & $\begin{array}{l}\text { Consensus was defined by } \geq 75 \% \text { of } \\
\text { the panel members voting either } \\
\text { 'strongly' or 'weakly' in favour of or } \\
\text { against a recommendation. The } \\
\text { strength of the recommendation } \\
\text { recommendation by default. }\end{array}$ \\
was determined to be 'strong' rather \\
than "weak" if $\geq 75 \%$ of the panel \\
rated a recommendation as 'strong'.
\end{tabular}

Abbreviations: GRADE, Grading of Recommendations Assessment, Development and Evaluation; ESCEO, European Society for Clinical and Economic Aspects of Osteoporosis, Osteoarthritis and Musculoskeletal Diseases; OA, osteoarthritis; OARSI, Osteoarthritis Research Society International.

${ }^{\sharp}$ Core treatments were defined as treatments appropriate for use by the majority of patients in nearly any scenario and deemed to be safe for use in conjunction with first-line and second-line treatments.

Table 2: Differences in OARSI and ESCEO recommendations for the non-surgical management of knee OA.

\begin{tabular}{|c|c|c|c|}
\hline Level or Stage & Intervention & OARSI & ESCEO \\
\hline \multirow[t]{3}{*}{ First-line treatments } & Topical NSAIDs & $\begin{array}{l}\text { Recommend use as } \\
\text { the first } \\
\text { pharmacological } \\
\text { intervention. }\end{array}$ & $\begin{array}{l}\text { Recommend use } \\
\text { after short-term } \\
\text { rescue analgesia } \\
\text { with paracetamol } \\
\text { (acetaminophen), } \\
\text { SYSADOAs and } \\
\text { physical therapy. }\end{array}$ \\
\hline & Paracetamol & $\begin{array}{l}\text { Conditionally } \\
\text { recommend against } \\
\text { the use of } \\
\text { paracetamol both in } \\
\text { the short and long } \\
\text { term. }\end{array}$ & $\begin{array}{l}\text { Recommend short- } \\
\text { term use ( } \leq 3 \mathrm{gm} / \text { day) } \\
\text { and, strongly advise } \\
\text { against use in the } \\
\text { long term. }\end{array}$ \\
\hline & SYSADOAs & $\begin{array}{l}\text { Strongly advise } \\
\text { against the use of all } \\
\text { glucosamine and } \\
\text { chondroitin } \\
\text { formulations } \\
\text { (including }\end{array}$ & $\begin{array}{l}\text { Recommend the use } \\
\text { of pharmaceutical- } \\
\text { grade glucosamine } \\
\text { sulfate and } \\
\text { chondroitin sulfate. }\end{array}$ \\
\hline
\end{tabular}




\begin{tabular}{|l|l|l|l|}
\hline & $\begin{array}{l}\text { pharmaceutical- } \\
\text { grade). }\end{array}$ & \\
\hline $\begin{array}{l}\text { Treatment in } \\
\text { patients with } \\
\text { persistent } \\
\text { symptoms }\end{array}$ & Opioids & $\begin{array}{l}\text { Strongly recommend } \\
\text { against the use of } \\
\text { oral and transdermal } \\
\text { opioids. }\end{array}$ & $\begin{array}{l}\text { Recommend the } \\
\text { short-term use of } \\
\text { weak opioids such } \\
\text { as tramadol. }\end{array}$ \\
\hline
\end{tabular}

Abbreviations: SYSADOA, symptomatic slow-acting drug for osteoarthritis. 


\section{Figure 1: Summary of voting procedures for the OARSI and ESCEO working groups.}

This schematic illustrates the voting procedures used by the working groups of the European Society for Clinical and Economic Aspects of Osteoporosis, Osteoarthritis and Musculoskeletal Diseases (ESCEO) and the Osteoarthritis Research Society International (OARSI) to reach consensus on their respective recommendations for the management of knee osteoarthritis (OA). The OARSI panel voted in two stages. In the first stage, they voted on the inclusion or exclusion of core treatments (that is, treatments appropriate for use in almost all patients and safe to use in combination with first-line and stage 2 treatments). Stage 2 involved up to three rounds of voting on the direction and strength of all remaining interventions. Contentious issues were discussed in online forum before re-voting. All interventions were assigned to one of seven levels, which determined the ordering of treatment provision and strength of the recommendations. The ESCEO panel voted on the direction and strength of proposed recommendations in a single stage of voting. All interventions were given either a strong recommendation or a weak recommendation.

Selection of core treatments
OARSI

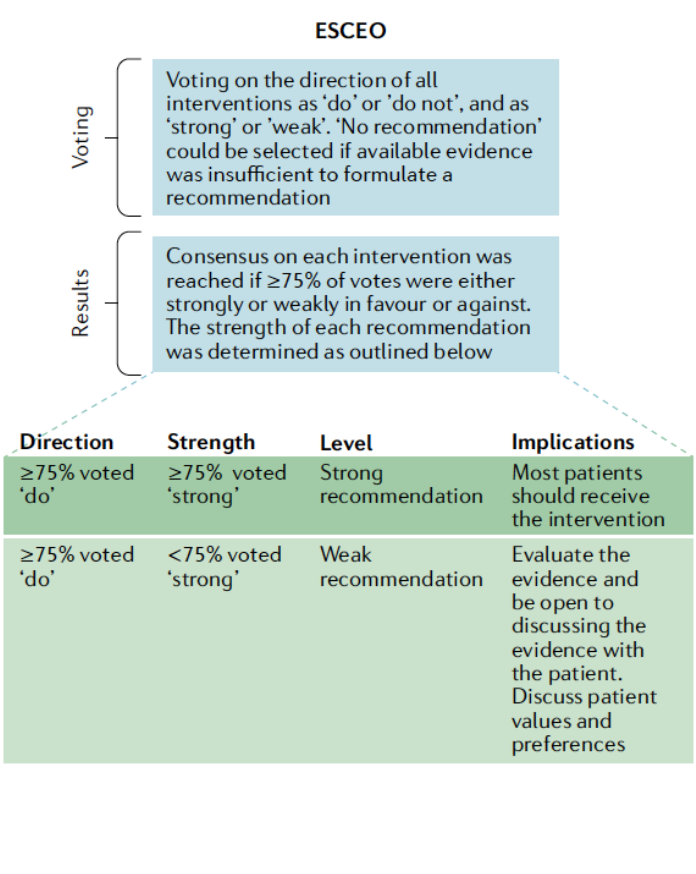


Figure 2: Simplified OARSI and ESCEO treatment algorithms for the non-surgical management of knee $\mathrm{OA}$ in patients without comorbidities. The list of treatments shown conforms to the recommended ordering of treatment provision in the updated 2019 guidelines for the management of knee osteoarthritis (OA) issued by the European Society for Clinical and Economic Aspects of Osteoporosis, Osteoarthritis and Musculoskeletal Diseases (ESCEO) and the Osteoarthritis Research Society International (OARSI). For the OARSI recommendations, physical assessments are performed as needed, before entry into the treatment algorithm. The treatments in stage 3 of the ESCEO algorithm represent the last pharmacological option before knee replacement surgery.

OARSI

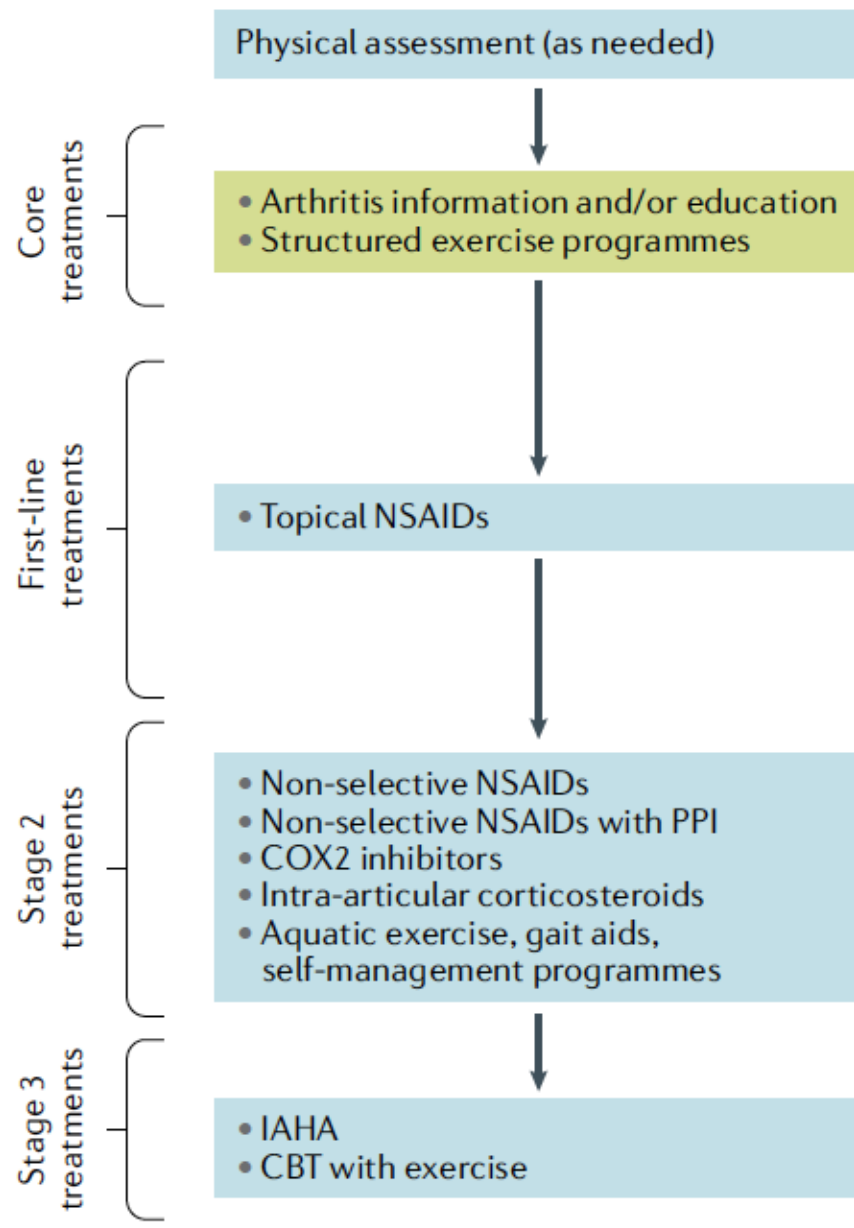

ESCEO

- Arthritis information and/or education - Structured exercise programmes

$\downarrow$
- Referral to health professionals plus
physical therapy
- SYSADOAs (pharmaceutical grade
glucosamine sulfate and/or chondroitin
sulfate)
- Low-dose, short-term paracetamol
- Topical NSAIDs for persistent symptoms
- Oral non-selective NSAIDs with PPI
- COX2-selective drugs and
non-selective NSAIDs
- Intra-articular corticosteroids and/or
IAHA
- Short-term, weak opioids
- Duloxetine

Abbreviations: non-steroidal anti-inflammatory drugs (NSAIDs), proton pump inhibitor (PPI), cyclooxygenase-2 (COX-2), symptomatic slow-acting drugs in osteoarthritis (SYSADOA). 